\title{
Actitudes implícitas hacia la violencia, conducta antisocial y consumo televisivo en estudiantes universitarios
}

\author{
Implicit attitudes towards violence, \\ antisocial behavior, and media consumption \\ in university students
}

\author{
Mariana Garín, Juan Huenchuleo, Nicolás Leal, Ana María Muñoz y Lucio Rehbein \\ Universidad de La Frontera, Temuco, Chile
}

\section{Resumen}

La alta frecuencia de exhibición de violencia en los medios de comunicación y sus efectos en la conducta de los espectadores ha sido estudiada desde diversos ámbitos, principalmente a través de medidas explícitas de autorreporte. En la presente investigación se indagó la relación entre las actitudes implícitas hacia la violencia, el comportamiento antisocial y el consumo televisivo, en un diseño transversal, mixto, correlacional y de diferencia de grupos. A los 33 participantes voluntarios se les administraron tres instrumentos: la Tarea de Asociación Implícita, el Cuestionario de Autorreporte de Comportamiento Social Adolescente y el Cuestionario de Consumo Televisivo. No se encontraron correlaciones estadísticamente significativas entre las variables; sin embargo, sí se encontró una significativamente mayor incidencia de conductas antisociales reportadas por los hombres que por las mujeres. Se discuten las implicancias de factores socioculturales que podrían incidir en el fenómeno estudiado.

Palabras clave: violencia, actitudes implícitas, conducta antisocial, consumo de medios, estudiantes universitarios.

\begin{abstract}
The highly frequent exhibition of violence in the media and its impact on the viewers' behavior has been studied from different approaches, but mainly through self-report explicit measures. In the present study, both implicit and explicit attitudes towards violence, antisocial behavior and television consumption were related, in a transversal, mixed, correlational and group difference design. The 33 participants were administered three instruments: the Implicit Association Task, the Self-Reported Questionnaire of Adolescent Social Behavior and a Sociodemographic and TV Consumption Questionnaire. No statistically significant relationships were found between the variables; however, significant differences were found in social behavior between men and women participants. The social and cultural factors that may be affecting the phenomena of media violence and aggressive social behavior are discussed.
\end{abstract}

Keywords: violence, implicit attitudes, antisocial behavior, media consumption, university students.

Contacto: L. Rehbein. Departamento de Psicología, Universidad de La Frontera, Av. Fco. Salazar 01145, Temuco. lucio.rehbein@ufrontera.cl Cómo citar este artículo:

Garín, M., Huenchuleo, J., Leal, N., Muñoz, A. M. y Rehbein, L. (2013). Actitudes implícitas hacia la violencia, conducta antisocial y consumo televisivo en estudiantes universitarios. Revista de Psicología, 22(2), 100-110. doi: 10.5354/0719-0581.2013.30857 


\section{Introducción}

La agresión, ya sea si es definida como un acto intencional de dañar a otra persona, o que busca evitar el daño (Baron y Richardson, 1994; Serrano e Iborra, 2005), o como el intento de mejorar la propia posición en una jerarquía de dominancia, a expensas de otra persona (Ferguson y Beaver, 2009), es una conducta consustancial a la especie humana, que ha estado presente en todas las culturas y en todas las épocas históricas.

Debido a la magnitud de los daños ocasionados en la población mundial, la violencia es actualmente considerada como un problema de salud pública. Se estima que cada año cerca de un 1,6 millones de personas pierde la vida en actos violentos ( $\sin$ considerar a las personas que resultan lesionadas $o$ heridas por esta causa), siendo las personas entre los 15 y los 44 años las que principalmente mueren en actos de violencia (Organización Panamericana de la Salud [OPS], 2002).

Comúnmente es posible observar diversos tipos de violencia, tales como el maltrato físico, el maltrato emocional, la negligencia, el abuso sexual, el maltrato económico y el vandalismo. En relación a los contextos donde se manifiesta la violencia, estos se pueden clasificar en: violencia doméstica; terrorismo político; acoso o bullying en las escuelas; acoso laboral y acoso sexual en el lugar de trabajo; genocidios y violaciones a los derechos humanos en situaciones de guerra, y aquella que se presenta en los medios de comunicación (Serrano e Iborra, 2005). Mientras que según a quien esté dirigida, se distinguen tres tipos de violencia: la autoinflingida, la interpersonal y la violencia colectiva (OPS, 2005).

Uno de los principales debates en torno a la violencia se refiere a las consecuencias derivadas de la exposición a contenidos violentos en los medios de comunicación. En este sentido Igartúa, (2002) señala que la exposición a la violencia puede afectar tanto a la victimización de las personas (miedo exagerado de ser violentado), como también a la posibilidad de desatar conductas de carácter violento y naturalizar este tipo de comportamiento.

Cabe destacar el carácter transcultural encontrado en la relación entre conducta agresiva y exposición a contenidos violentos en los medios de comunicación, puesto que dicha relación se ha observado en diversos contextos culturales: Estados Unidos, Polonia, Sudáfrica, Australia, entre otros (Igartúa, 2002).

Uno de los instrumentos que permite evaluar conductas violentas es el Cuestionario de Autorreporte de Comportamiento Antisocial en Adolescentes (CACSA), el cual se encuentra validado para la población chilena y posee importantes fortalezas psicométricas (Alarcón et al., 2010). Este cuestionario explora dimensiones de la conducta como comportamiento prosocial, comportamiento antisocial total y victimización de abuso.

El comportamiento prosocial es entendido como aquel acto de ayudar o beneficiar a otra persona o grupo, sin la existencia de recompensa. Estas acciones a menudo suponen algún costo, riesgo o autosacrificio por parte de quien la ejerce, con o sin una motivación altruista (González, 2000). Mientras que la conducta antisocial alude a todas aquellas conductas que reflejen una violación de normas o reglas sociales, o constituyan actos contra otras personas sin importar la gravedad de estos. Incluye un amplio rango de comportamientos, como destrucción de la propiedad pública o privada, crueldad con personas o animales, mentira, provocación de fuego, peleas o ataques físicos, robos, etc. Pueden expresarse tanto en conductas abiertamente expuestas como también en conductas encubiertas (Silva, 2003).

Diversos estudios demuestran que la etapa de la adolescencia es el período de mayor prevalencia de conductas antisociales (Serrano, El Astal y Faro, 2004), siendo las transgresiones leves las conductas más frecuentes en esta etapa, concentrándose mayoritariamente en los grupos de adolescentes varones. En contraposición, las mujeres tendrían mayor predominio de comportamientos prosociales en la adolescencia (Inglés et al., 2009).

Según Gunter (1996), existe evidencia de estudios correlacionales, longitudinales y experimentales que señalan a los medios de comunicación como un facilitador de la conducta violenta, en el sentido que sirven como puente entre la información expuesta en los medios de comunicación (contenido violento) y la conducta reportada por los individuos que se exponen a dicho contenido.

En Chile, en el año 2002, el Consejo Nacional de Televisión publicó el estudio denominado "Violencia en televisión: el gran debate", el cual aportó datos interesantes sobre la programación chilena. Por ejemplo, allí se señaló que el 34\% del contenido del noticiero (dejando fuera deporte y culturaespectáculos), estaban referidas a actos violentos y criminalidad; mientras que se detectó la presencia de violencia en $89.4 \%$ de la oferta de dibujos animados analizados; así mismo un $92.1 \%$ de la oferta de películas en televisión abierta presentaba algún nivel de violencia explícita (Navarro, 2003). En términos similares, una investigación desarrollada el año 2008 por la misma institución reveló que el 61.5\% de los estudiantes de la muestra, entre 18 y 29 años veía televisión abierta durante un promedio diario de 132.7 minutos, los días que veían televisión durante la semana; en tanto el $65.2 \%$ de los estudiantes veía televisión satelital, promediando $151.6 \mathrm{mi}$ nutos de consumo diario, los días que veían televisión durante la semana (Consejo Nacional de Televisión, 2009). 
En general, a nivel internacional, existe un extenso cuerpo de estudios que ha abordado la búsqueda de evidencia respecto a si la teleexpectación de violencia puede causar comportamiento agresivo y puede cultivar valores que favorezcan el uso de la agresión en la resolución de conflictos (Murray, 2008). En efecto, Pecora, Murray y Wartella (2007) en una revisión de las investigaciones realizadas sobre este tema en los últimos 50 años, concluyen que existe un impacto indesmentible de la violencia experimentada como espectador, sobre la propia conducta agresiva en los niños. Por otra parte, en un estudio reciente Ferguson, Ivory y Beaver (2013), señalan que la exposición a violencia en los medios constituye un factor lejano y desestimable, frente al potente rol de la interacción entre factores genéticos y sociales proximales como son las influencias de la familia y de la escuela, en cuanto predictores de la criminalidad en la adultez (Ferguson, Ivory y Beaver, 2013).

En consecuencia, y a pesar de la gran variedad de estudios en torno a la violencia, con énfasis en sus distintas manifestaciones, se carece de datos objetivos que permitan conocer las evaluaciones generales que las personas realizan sobre la atracción o rechazo que les provoca este tipo de contenidos, ya sea cuando son transmitidos en los medios, o cuando la violencia ocurre en el tráfago de la vida cotidiana. En palabras de Petty y Wegener (1998), son escasas las investigaciones que permiten conocer las actitudes implícitas de las personas ante la violencia.

Según Allport (1935), una actitud es una disposición mental o neurológica de preparación para la acción, que se organiza según la experiencia y que ejerce una influencia directiva sobre las conductas hacia todos los objetos y situaciones con que se relaciona.

Por otra parte, las actitudes implícitas son evaluaciones activadas automáticamente ante el objeto actitudinal, pero que tienen un origen desconocido para el sujeto. Sin embargo, se sabe que su formación requiere de una cierta historia de presentaciones y evaluaciones previas, y que una vez formadas, influyen de manera automática e involuntaria en las respuestas de las personas (Greenwald y Banaji, 1995; Wilson, Lindsey y Schooler, 2000).

Normalmente, las actitudes se han medido mediante procedimientos de autoinforme, como en las escalas de diferencial semántico y las escalas tipo Likert (Petty y Cacioppo, 1986). Este tipo de métodos de evaluación han sido objeto de críticas debido a limitaciones tales como las diferencias entre las personas en su capacidad para darse cuenta, o ser conscientes, de sus propias actitudes y estados internos; y la deseabilidad social que puede introducir un sesgo en las respuestas de los sujetos. Además, incluso cuando las personas tienen claridad acerca de sus actitudes, no siempre se muestran dispuestas a revelarlas de manera explícita (Briñol, De la Corte y Becerra, 2001).

Debido a las limitaciones que presentan los procedimientos de autorreporte, se han creado instrumentos que permiten medir las actitudes de una manera implícita, posibilitando el acceso a los estados internos y actitudes de las personas, sin que se les necesite preguntar de manera directa. Los instrumentos más conocidos y utilizados para la medición de actitudes implícitas son la Tarea de Evaluación Automática (Fazio y Olson, 2003; Fazio, Sanbonmatsu, Powell y Kardes, 1986); y la Tarea de Asociación Implícita (TAI), creada por Anthony Greenwald (Greenwald y Banaji, 1995). Ambas tareas permiten inferir el grado de aceptación o rechazo a determinados contenidos, a través de los tiempos de reacción del evaluado. En el caso de la TAI, el efecto se observa en la fase incompatible, por cuanto decidir entre dos conceptos diana que son incompatibles, o incongruentes entre sí, requiere que el sujeto opere bajo una mayor carga cognitiva, lo que se refleja inevitablemente en tiempos de reacción más largos (Greenwald, McGhee y Schwartz, 1998; Greenwald y Nosek, 2001).

En términos específicos y utilizando una Tarea de Asociación Implícita especialmente diseñada para la presente investigación, se buscó responder a la pregunta: ¿existe relación entre las actitudes implícitas hacia la violencia y el comportamiento antisocial, en estudiantes universitarios? Otras dos preguntas, subsidiarias a la anterior, que se buscó responder son: ¿existen diferencias en las actitudes implícitas hacia la violencia entre estudiantes hombres y mujeres?, y ¿existe diferencia en las actitudes hacia la violencia según el consumo televisivo de los participantes?

En términos operacionales, el objetivo general del estudio fue constatar la relación entre actitudes implícitas hacia la violencia y comportamiento antisocial autorreportado en una muestra de estudiantes de la Universidad de La Frontera. Mientras que los objetivos específicos fueron: (a) Constatar si existe relación entre las actitudes implícitas hacia la violencia y la conducta antisocial reportada por los estudiantes. (b) Constatar si existe relación entre las actitudes implícitas hacia la violencia y el número de horas de consumo televisivo reportado por los estudiantes de la muestra. (c) Establecer si existe una correlación positiva significativa entre conducta antisocial autorreportada y consumo televisivo. (d) Establecer si existen diferencias significativas en las actitudes implícitas hacia imágenes violentas entre hombres y mujeres de la muestra; y (e) Establecer si había diferencias significativas entre hombres y mujeres respecto a la conducta antisocial autorreportada. 
De los objetivos recién expuestos, se derivaron las siguientes hipótesis:

H1: Existe una correlación negativa significativa entre los tiempos de reacción en la TAIv y las puntuaciones en conducta antisocial de los participantes.

H2: Existe una correlación negativa significativa entre los tiempos de reacción en la TAIv y el consumo de violencia televisiva de los participantes.

H3: Existe una correlación positiva significativa entre conducta antisocial autorreportada y consumo televisivo.

H4: No existen diferencias significativas en los tiempos de reacción en la TAIv, entre los participantes hombres y mujeres de la muestra.

H5: Existen diferencias significativas en el puntaje de comportamiento antisocial entre hombres y mujeres de la muestra.

Para poner a prueba estas hipótesis se utilizó un diseño transversal mixto (correlacional y de diferencia de grupo), de medición única. La variable independiente del estudio fue la exposición a imágenes violentas y no violentas; mientras que la variable dependiente fue el tiempo de reacción o efecto TAI (actitudes implícitas hacia la violencia). Se registraron como medidas adicionales el puntaje obtenido por los participantes en conducta antisocial reportada y el índice de consumo televisivo. Por último, se utilizó el sexo como variable de agrupamiento.

\section{Método}

\section{Participantes}

Los participantes fueron 33 estudiantes voluntarios provenientes de los primeros y segundos años de cuatro facultades de la Universidad de La Frontera. De estos, 16 (48.5\%) eran hombres y 17 (51.5\%) eran mujeres, con un promedio de edad de 18.7 años.

\section{Instrumentos}

En el presente estudio se utilizaron los siguientes instrumentos para la generación y la captura de los datos: (a) la Tarea de Asociación Implícita (TAI), (b) el Cuestionario de Autorreporte de Conducta Social Adolescente (CACSA); y (c) el Cuestionario de Consumo Audiovisual.

a) Tarea de Asociación Implícita. Para la medición de las actitudes implícitas hacia la violencia fue necesario construir una versión modificada de la TAI, de modo tal que, manteniendo el procedimiento estándar de la tarea, fuera posible presentar a los y las participantes, imágenes y conceptos ante los cuales pequeñas diferencias en los tiempos de reacción (milisegundos), reflejaran su grado de aceptación (o rechazo) ante el estímulo. En adelante esta versión ad hoc de la tarea será denominada TAIv.

El diseño y administración de las series de estímulos así como el registro de los tiempos de reacción de cada respuesta de los participantes se realizó mediante el uso de la aplicación computacional especializada denominada E-Prime ${ }^{\star}$ de Psychology Software Tools Inc.

La TAIv fue construida con imágenes y conceptos especialmente seleccionados por los investigadores y ratificados por jueces, de manera tal que permitía la presentación aleatoria y contrabalanceada de imágenes con contenido violento y no violento, y pares de conceptos diana (conceptos que el o la participante debía clasificar). Los conceptos diana utilizados fueron: "violencia" y "no violencia", y "agradable" y "desagradable". Además se utilizaron atributos asociados a los conceptos diana: paz, amor, bienestar, felicidad, para no violencia/agradable; y odio, tristeza, dolor, ira, para violencia/desagradable. Los conceptos diana, según la fase del experimento, aparecían en la pantalla del computador en la parte superior izquierda o derecha, mientras que los atributos y las imágenes asociadas a cada concepto, aparecían en el centro del monitor.

La TAIv estaba compuesta por dos etapas, una etapa compatible y otra incompatible, cada una con 64 ensayos. La etapa compatible constaba de tres fases y se caracterizaba por facilitar las asociaciones fuertes (o compatibles) entre los pares de conceptos diana y sus atributos e imágenes, permitiendo una clasificación fácil y rápida. Al inicio de cada ensayo, aparecía en el cuadrante superior izquierdo del monitor, la palabra "violencia", e inmediatamente debajo, la palabra "desagradable"; mientras que en el cuadrante superior derecho de la pantalla, aparecía la palabra "no violencia", con la palabra "agradable". En cada ensayo el/la participante debía clasificar la imagen o el atributo que aparecía en el centro del monitor con los conceptos de la izquierda o de la derecha, según el contenido de la imagen, o según la similitud semántica del atributo. Así, en el caso de las imágenes, la clasificación procedía entre los conceptos diana "violencia" y "no violencia"; mientras que en el caso de los atributos, la clasificación procedía entre los conceptos diana "desagradable" o "agradable". La respuesta de clasificación de imágenes y atributos con respecto a los conceptos diana por parte del o de la participante debía ocurrir en el menor tiempo posible y era emitida presionando la tecla superior izquierda del teclado (correspondiente a la letra Q), si la imagen o atributo corresponde al concepto del lado izquierdo de la pantalla; o la tecla del otro extremo del teclado (correspondiente a la letra P), si la imagen o atributo correspondía al concepto del lado derecho de la pantalla, utilizando el dedo índice de la mano izquierda o derecha, respectivamente. 
La etapa incompatible constó de dos fases en la que se facilitaban asociaciones débiles (o incompatibles) entre los conceptos diana, atributos e imágenes. En esta etapa aparecían en el lado izquierdo del monitor, la palabra "no violencia" con la palabra "desagradable" bajo ella; y al lado derecho del monitor, la palabra "violencia", y debajo, la palabra "agradable", debiendo proceder la tarea de clasificación de la misma forma que en la etapa anterior.

La incompatibilidad, que se manifiesta por la presentación conjunta de los conceptos diana "violencia/agradable" y "no-violencia/ desagradable", impone una mayor demanda cognitiva a la persona que responde, cuando debe clasificar los diferentes atributos e imágenes, lo que se refleja en una mayor lentitud en su proceso de clasificación, y consecuentemente, tiempos de reacción más largos. Sin embargo, para quienes tienen una actitud implícita favorable al tema evaluado, la presentación conjunta de estos conceptos diana no representa una incompatibilidad, y por lo tanto, no se les dificulta la clasificación y responden en un tiempo menor, que las personas que tienen una actitud implícita desfavorable al tema evaluado (Greenwald y Banaji, 1995). Una ilustración esquemática de las fases del experimento, inspirada en una ilustración similar utilizada por Cantera y Gamero (2007), se presenta en la figura 1 .

Las imágenes utilizadas en el TAIv, fueron seleccionadas por tres jueces, un hombre y dos mujeres, quienes a través de un ranking de 0 a 5, donde 0 representaba ausencia total de violencia, y 5 representaba máxima violencia, determinaron el nivel de violencia que presentaba cada imagen. De un total de 16 imágenes violentas y 14 imágenes no violentas, se seleccionaron las 7 imágenes menos violentas y las 7 imágenes más violentas para formar parte del TAIv. Respecto a los atributos asociados a los conceptos diana, se resguardó que estos fueran de similar valencia.

Según estudios anteriores, el instrumento TAI posee propiedades psicométricas que resultan suficientemente robustas con altas correlaciones entre TAI y priming automático lo que apoyan la validez convergente; mientras que la fiabilidad test-retest se ha visto que fluctúa en alrededor de un $\mathrm{r}$ $=.60$ (Briñol, Horcajo, Becerra, Falces y Sierra, 2002).
Fase 1

\begin{tabular}{|c|c|}
\hline Violencia & No Violencia \\
\hline & Imágenes \\
\hline
\end{tabular}

16 ensayos
Fase 2

\begin{tabular}{|c|c|}
\hline Desagradable & Agradable \\
& Atributos \\
\hline & 16 ensayos
\end{tabular}

Fase 3

\begin{tabular}{|lc|}
\hline $\begin{array}{l}\text { Violencia } \\
\text { Desagradable }\end{array}$ & $\begin{array}{c}\text { No Violencia } \\
\text { Agradable }\end{array}$ \\
& Imágenes \\
& Atributos \\
& \\
\hline 32 ensayos +32 \\
Etapa Compatible
\end{tabular}

Fase 4

\begin{tabular}{|cc|}
\hline No Violencia & Violencia \\
& \\
& \\
& \\
& \\
\hline & \\
& \\
& \\
\hline
\end{tabular}

Fase 5

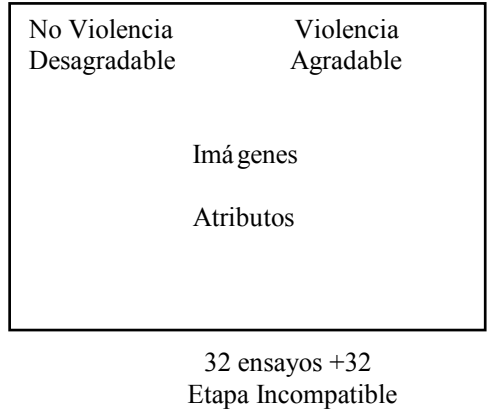

Figura 1. Fases de TAI. 
Las actitudes implícitas fueron medidas a través de los tiempos de respuesta promedio que registraron los sujetos en cada una de las fases del instrumento.

b) El Cuestionario CACSA. Este instrumento, construido por Alarcón et al. (2010), está constituido por 56 ítems con formato de respuestas tipo Likert. El cuestionario está dirigido a población adolescente para detectar comportamiento social adaptativo y transgresor, a través de la medición de tres dimensiones principales: Comportamiento Prosocial “CPRO”, Comportamiento Antisocial Total “CAT” y Víctima de Abuso de Poder "VAP". Consta, además, de una escala de deseabilidad social (10 ítems), de respuesta dicotómica V/F, con el fin de controlar esta variable (Alarcón et al., 2010). El cuestionario incluye también un anexo con preguntas sociodemográficas. Para el presente estudio solo se utilizó la escala CAT y los datos sociodemográficos de edad, sexo y curso.

c) El Cuestionario de Consumo de Medios. Este cuestionario fue construido por los investigadores, y está orientado a averiguar el consumo televisivo, reportado en términos de un promedio de horas diarias, a través de la selección de uno de los siguientes valores promedio 1, 3, 5 o 7 horas diarias. El cuestionario proporcionaba asimismo información sobre el contenido programático favorito del participante al que se le asignó un factor de ponderación a priori, según su probabilidad de contener escenas de violencia, quedando como sigue: Terror (x5), Acción (x4), Drama (x3), Comedia y Reportaje (x2), e Infantiles (x1). La puntuación máxima de este índice está dada para personas que ven un promedio de 7 horas de programas de terror (35 puntos); mientras que la más baja, está dada para personas que ven en promedio 1 hora de programas infantiles (1 punto).

\section{Procedimiento}

Los participantes fueron contactados de manera incidental en pasillos y casinos de la universidad, se les invitó a participar voluntariamente, y en caso de aceptar, se les informó en qué consistía la investigación y firmaron un consentimiento informado. Se procedió de esta manera hasta completar un número similar de participantes hombres y mujeres por facultad, hasta un máximo de 34 estudiantes. La administración de los instrumentos se realizó de manera individual, en el Laboratorio de Psicología Básica de la Universidad de La Frontera, bajo condiciones de aislamiento y de baja distractibilidad.
En primer lugar se procedió a familiarizar a los participantes con el procedimiento de clasificación en una sesión de práctica con el TAIv, la que era seguida, luego de un breve descanso, por la administración definitiva de la tarea.

A continuación se les pedía que contestasen el CACSA y el anexo que incluía preguntas de tipo sociodemográfico; y por último, contestaban el Cuestionario de Consumo Televisivo. Se siguió esta misma secuencia de administración de instrumentos para todos los sujetos. En retribución por su participación, se entregó a cada participante una barra de $80 \mathrm{~g}$ de chocolate, al finalizar la sesión.

\section{Resultados}

Una vez importados los datos del TAIv desde E-Prime, se procedió a limpiar la base de datos eliminando del análisis aquellas respuestas con tiempos de reacción inadecuados, aquellas demasiado rápidas (por debajo de los 300 milisegundos) o demasiado lentas (sobre 3000 milisegundos), por cuanto estarían reflejando respuestas de tipo anticipatorio o demasiado controlado, respectivamente (Cárdenas y Barrientos, 2008).

Para los análisis estadísticos con los datos de la TAIv, se procedió a reescalar la variabilidad intrasujeto en un nuevo puntaje 'D', mediante el procedimiento utilizado por Greenwald, Nosek y Banaji (2003). El puntaje 'D' es la diferencia en milisegundos entre las latencias ante los ensayos congruentes y los incongruentes, dividida por la desviación típica de la distribución de latencias de las dos medidas combinadas. Según sus proponentes, esta transformación de puntajes tiene la ventaja de: (a) reducir la variabilidad de la medición resultante de la destreza en la velocidad de respuesta; (b) reforzar las diferencias individuales relacionadas con la fuerza asociativa; y (c) reducir la mezcla de efectos cognitivos que dificultan la interpretación de los resultados (Greenwald, Nosek y Banaji, 2003).

Los datos del CACSA, del Cuestionario de Consumo Televisivo y los datos sociodemográficos, fueron digitados a la misma base y se procedió al cálculo de las medidas de tendencia central de las variables evaluadas, utilizando el programa estadístico SPSS, versión 20.0. Los resultados de estos cálculos se presentan en la tabla 1. 
Tabla 1

Promedios y desviaciones típicas de los tiempos de reacción en la TAIv (ms), y de las puntuaciones obtenidas en el CACSA y el Cuestionario de Consumo Televisivo

\begin{tabular}{cccc}
\hline Tipo de variable medida & $\mathrm{N}$ & Media & D. Típica \\
\hline Tiempo (ms) de reacción en la TAIv & $31^{\mathrm{a}}$ & 0.125 & 0.27 \\
Hombres & 15 & 0.02 & 0.47 \\
Mujeres & 16 & 16.4 & 0.37 \\
Conducta Antisocial (CACSA) & $32^{\mathrm{a}}$ & $21.3^{\star}$ & 10.8 \\
Hombres & 16 & 11.6 & 8.0 \\
Mujeres & 16 & 6.3 & 3.3 \\
Índice de Consumo de Medios & 33 & 7.1 & 3.1 \\
Hombres & 16 & 5.5 & 4.1 \\
\hline
\end{tabular}

Nota:

a La cantidad de sujetos en estas variables se vio afectada por la eliminación de puntajes extremos.

*Puntuación significativamente superior a la de la población de referencia, $p<.05$.

Respecto a las hipótesis sobre diferencias de grupos, no se encontraron diferencias significativas entre hombres y mujeres en las variables Actitud Implícita y Consumo Televisivo; mientras que en la variable Conducta Antisocial esta diferencia fue altamente significativa, $U(33)=72.5 ; p=.02$, lo que permite aceptar la hipótesis $n^{\circ} 5$ del estudio.

En relación a la distribución relativa de los participantes con respecto a sus actitudes implícitas hacia la violencia, según estas se reflejaron en las puntuaciones obtenidas en la TAIv, se encontró que 24 participantes $(72.7 \%)$ presentaron actitudes implícitas desfavorables hacia los estímulos representativos de violencia; mientras que 9 participantes (27.3\%), mostraron tener actitudes implícitas favorables hacia la violencia (ver figura 2).

Por otra parte, en lo referente a los puntajes obtenidos en conducta antisocial autorreportada, los hombres de la muestra obtuvieron puntuaciones superiores a las de las mujeres, marcando incluso una tendencia a puntuar por sobre su población de referencia (datos normativos); mientras que las mujeres promediaron más bajo que los hombres, y similares a los de su población de referencia (ver tabla 1).

En tercer lugar, se procedió a calcular los coeficientes de correlación Rho de Spearman entre las variables dependientes. Los resultados obtenidos indican que la correlación entre Actitudes Implícitas hacia la Violencia (expresadas por los valores promedio de las diferencias de los tiempos de reacción de cada participante entre los ensayos congruentes e incongruentes en la TAIv; ver figura 2) y Conducta Antisocial, no fue significativa, por lo que la primera hipótesis del estudio fue rechazada. De un modo similar, al no encontrarse una asociación significativa entre Actitudes Implícitas hacia la Violencia y Consumo Televisivo, y tampoco entre Conducta Antisocial y Consumo Televisivo, se rechazaron las hipótesis 2 y 3 del estudio. Sin embargo, cuando se desagregó la muestra según sexo, se encontró que los hombres mostraban una tendencia a relacionar de manera directa y significativa las últimas dos variables (Conducta Antisocial y Consumo Televisivo), obteniéndose un coeficiente $r(16)=$ $0.44, p=.03$, relación que no fue encontrada para las mujeres de la muestra.

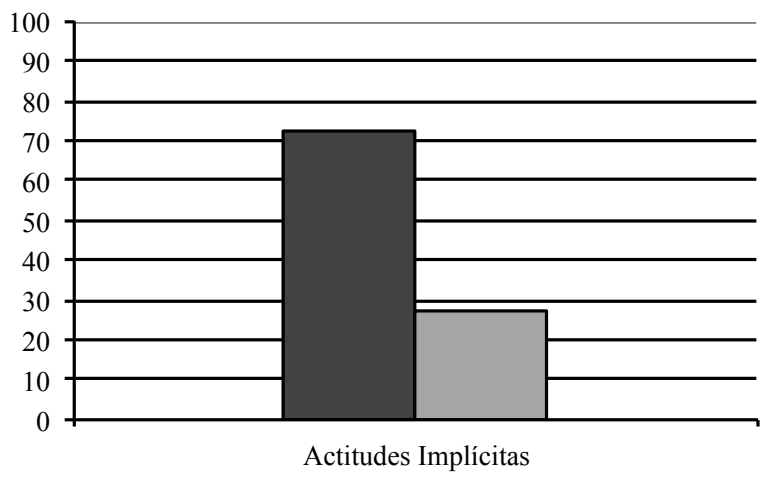

Actitud Desfavorable $\square$ Actitud Favorable

Figura 2. Distribución porcentual de la muestra según sus actitudes implícitas (de aceptación o rechazo) hacia escenas violentas. 


\section{Discusión}

A modo de resumen de los resultados, cabe señalar que la medición de actitudes implícitas hacia la violencia no correlacionó de manera significativa con las puntuaciones en conducta antisocial, ni con los índices de consumo televisivo de los participantes, como se esperaba y se había predicho en las hipótesis. Estos resultados, en general, negativos, tuvieron algunos indicios interesantes, aunque difíciles de interpretar, como el hecho que solo una fracción menor de los participantes (27.9\%) mostró actitudes implícitas favorables hacia los estímulos violentos, y de estos, el 66\% fueron mujeres; y que a pesar que en el total de los participantes no se encontró una correlación directa y significativa entre Conducta Antisocial autorreportada y Consumo Televisivo, al desagregar los datos por sexo, se encontó una correlación altamente significativa entre las dos variables en los participantes hombres. Por último, la única hipótesis que pudo ser aceptada es la que predecía diferencias entre hombres y mujeres en Conducta Antisocial, donde los participantes hombres puntuaron significativamente más alto que las mujeres, e incluso, más alto que su grupo normativo de referencia; mientras que las mujeres no difirieron de su norma. Estos resultados serán discutidos según las particularidades metodológicas del estudio y los antecedentes aportados por estudios precedentes.

Como ya fuera dicho, los resultados obtenidos en el estudio no concuerdan con lo planteado en la literatura, no encontrándose una relación entre las medidas de actitudes implícitas y explícitas hacia la violencia, y el consumo televisivo de programas con elevados índices de violencia. Según lo planteado por Igartúa (2002), se esperaba que quienes obtuvieran un mayor consumo televisivo presentaran, a su vez, mayor puntaje de conducta antisocial, como también actitudes implícitas favorables hacia la violencia. Por otra parte, y en la misma línea, Gunter (1996) señaló que, a mayor tiempo de exposición a contenidos violentos existiría una mayor facilitación de la conducta antisocial. Esta ausencia de facilitación en los actuales resultados podría explicarse, por una parte, debido a una posible influencia de la deseabilidad social en las respuestas. Concretamente, siendo todos los participantes estudiantes universitarios, podrían no estar dispuestos a revelar a los investigadores la cantidad de su tiempo destinado a ver TV y/o la magnitud de la violencia en sus programas preferidos.

A pesar de las consideraciones antes mencionadas, cabe señalar que, en un análisis retrospectivo, una de las principales debilidades de este estudio radica en la inadecuada y poca confiable medición del consumo televisivo con programación violenta. A este respecto, cabe recordar que no se preguntó directamente a cada participante por los programas específicos vistos en un período determinado; solo se le pidió que señalara la categoría de programas que prefería ver y cuánto tiempo (horas) veía televisión a la semana.
La falta de robustez en la medición de esta variable queda en evidencia al haber supuesto, por ejemplo, que los dibujos animados portan el nivel más bajo de contenido violento, cuestión que si se observa la parrilla programática televisiva, no es efectiva y así lo evidencia el propio Consejo Nacional de Televisión en su estudio de 2002. Por otra parte, se pasó por alto que para cualquier persona resulta difícil estimar el tiempo que utiliza viendo televisión de forma activa. En la práctica es probable que se dé una tendencia azarosa, tanto a sobreestimar como a subestimar esos tiempos.

En consecuencia, y en retrospectiva, quizás otro tipo de medida, como darles guías de programación y pedirles que indiquen qué vieron en una semana, podría haberse acercado mejor a los objetivos del estudio. O de manera alternativa, sería pertinente utilizar instrumentos de medición más pormenorizada y confiable para indagar este tipo de información, como es el recientemente construido por Del Valle, Denegri y Chávez (2012).

En otro orden de cosas, la ausencia del efecto facilitador de la exposición a contenidos violentos en los medios podría atribuirse a la naturalización de dichos contenidos (Cabero, 2002), a consecuencia de la permanente exposición a estos que experimentan las nuevas generaciones de jóvenes, no provocando ya una influencia en la conducta manifiesta y/o implícita. Además, los estudios que confirman la relación entre la exposición a contenidos violentos y comportamiento agresivo se basan en una visión conductista de esta, no considerando la influencia de factores de tipo biopsicosociales (como el temperamento, aprendizaje, relaciones con el entorno, creencias, valores, entre otros), que sí pudieran influir de manera más directa sobre el comportamiento de las personas. Cabero (2002), indica que la exposición a escenas violentas no afecta a todos por igual, ni en el mismo sentido, y que son más importantes los factores sociales (cultura) que los medios de comunicación, siendo los contenidos expuestos en estos últimos, un reflejo de lo que ocurre en la sociedad (Cabero y Romero, 2001).

Por otro lado, se encontraron medias elevadas y superiores a la población de referencia (Alarcón et al. 2010), en la puntuación de conducta antisocial en hombres. Lo anteror indicaría que, a pesar de que no hubo correlaciones directas y significativas entre actitudes implícitas favorables hacia la violencia y conducta antisocial; y entre conducta antisocial y consumo televisivo, estos resultados podrían explicarse por lo planteado por Cabero (2002) quien señala que la observación de actos violentos crea insensibilidad ante estos, asumiendo que son actos usuales dentro de nuestra sociedad, no implicando una valoración favorable o desfavorable ante ellos. 
Por otra parte, se encontró que existen diferencias significativas entre hombres y mujeres en conducta antisocial explícita reportada. Esta constatación de perfiles estereotipados típicos de "mujeres preponderantemente prosociales y hombres mayoritariamente agresivos", es habitualmente observada en muestras de participantes voluntarios y han sido descritos en otros investigaciones anteriores (e.g., Berger, 2011; Chóliz, 2002). Sin embargo, la teoría indica que la conducta manifiesta está racionalizada (Cárdenas y Barrientos, 2008), es decir, es una conducta más controlada y no refleja la verdadera evaluación que tienen las personas respecto a un tema, al contrario de lo que ocurre con las actitudes implícitas o respuestas automáticas, que permiten acceder a los estados internos de las personas, sin filtros, pudiendo conocer sus verdaderas actitudes. Cabe suponer que es por esta razón por la que en nuestro estudio aparecen las mujeres con menor conducta antisocial con relación a los hombres, lo que no se refleja en la medida implícita, donde ambos presentan actitudes similares, en relación a la violencia.

Entre las limitaciones del estudio cabe mencionar, en primer lugar, la naturaleza ambigua de "la violencia" como objeto actitudinal, y en consecuencia, la ambigüedad de los reactivos del experimento. Específicamente, se utilizaron escenas donde se ejecutaban acciones violentas, sin embargo al ser imágenes estáticas y presentadas por una fracción de segundo, estas podían ofrecer una cierta ambigüedad al momento de ser clasificadas de manera rápida y categórica. De hecho, los jueces que seleccionaron estas imágenes, tuvieron un tiempo de observación mucho más prolongado que los propios participantes. Sin embargo, la técnica de asociación implícita requiere de tiempos muy breves de exposición, con el propósito de elicitar respuestas automáticas, a través de las cuales inferir las actitudes implícitas hacia los estímulos. En otras palabras, es posible que el procedimiento del Test de Asociación Implícita que fuera utilizado en este estudio no sea apto para evaluar actitudes implícitas hacia la violencia, en general, de manera similar a como ha probado ser apto para medir actitudes implícitas hacia otros objetos actitudinales, como por ejemplo, la violencia de género (Cantera y Blanch, 2010), los hombres homosexuales (Cárdenas y Barrientos, 2008), las preferencias electorales (Ayala, 2012), entre otros.

Una segunda limitación, se relaciona con el complejo procedimiento de presentación de reactivos y requerimientos de respuesta en las diferentes fases del experimento. Una reflexión a posteriori, permite concluir que, posiblemente, se requerió de un proceso de familiarización y práctica previa bastante más extenso que el efectivamente utilizado para lograr un desempeño verosímil y confiable de cada participante en el TAIv. En otras palabras, es posible que esta variable haya contaminado los resultados, implicando que no todos los sujetos hayan entendido de manera adecuada la dinámica de las respuestas, especialmente en la fase incongruente del test.
A su vez, la intervención de otras variables extrañas como el haber administrado el test a algunos participantes de manera oportunista en ambientes diferentes al laboratorio, también pudieran haber influido en los resultados encontrados; y finalmente, y en particular debido a las variables contaminantes recién mencionadas, hubiese sido muy conveniente contar con una mayor cantidad de participantes de ambos sexos.

En cuanto a líneas futuras de investigación se propone, en primer lugar, explorar la manera de afinar los procedimientos y tareas del TAI, con el propósito de tornarlo en un instrumento más válido y confiable para la medición de las actitudes implícitas a la violencia (ver limitaciones señaladas en párrafos anteriores). En este mismo marco de afinamiento de las mediciones, buscar maneras de integrar al estudio de las actitudes implícitas hacia la violencia, otras técnicas como el diferencial semántico y entrevistas en profundidad, que posibiliten una comprensión integral de los factores específicos que influyen en el comportamiento antisocial y la actitud favorable hacia la violencia, para así tener las herramientas para poder intervenir sobre ellos.

Por otra parte, todo comportamiento humano, incluidas la agresión y la violencia, son el resultado de complejos procesos que tienen lugar en el cerebro. Y dado que las conductas violentas pueden ser el resultado de condiciones relativamente permanentes o de estados temporales, sería de interés investigar los correlatos neurológicos asociados a la expectación de violencia televisada. Estudios neuropsicológicos como estos podrían ser clave para la comprensión de las formas en que los niños podrían responder a la violencia vista como entretenimiento, y ayudar a entender cómo ocurre el efecto de desensibilización a la violencia. De hecho, un estudio piloto de Murray et al. (2006) demostró que la visión de violencia televisada recluta de manera selectiva varias estructuras del hemisferio derecho que se han probado involucradas en la activación del organismo frente a la amenaza, lo que sugiere un procesamiento significativamento emocional de la violencia televisada (Murray, 2008).

En consecuencia, si bien la presente investigación constituye un esfuerzo original en nuestro medio, por asociar las actitudes implícitas hacia la violencia con las mediciones explícitas de conducta antisocial, en función de la violencia vista en los medios televisivos, los resultaos encontrados son básicamente no concluyentes. No obstante lo anterior, se estima que este estudio tiene el mérito de dar inicio a líneas de investigación que utilicen el paradigma y las técnicas de medición de actitudes implícitas para profundizar en aspectos de relevancia aplicada en torno a la violencia, ya sea a nivel de programas de intervención en salud mental, como en la gestión de los medios de comunicación. 


\section{Referencias}

Alarcón, P., Pérez-Luco, R., Salvo, S., Roa, G., Jaramillo, K. y Sanhueza, C. (2010). Validación del Cuestionario de Autoreporte de Comportamiento Antisocial en Adolescentes: CACSA. Paidéia, 20, 291-302.

Allport, G. W. (1935). Attitudes. En Fiske, S. T., Gilbert, D. T. y Lindzey, G. (Eds.), A Handbook of Social Psychology (pp. 798844). Worchester, MA: Clark University Press.

Ayala, A. (2012). La utilización del Test de Asociación Implícita en los procesos electorales. Revista Derecho Electoral, Cuarta Época, 1(10), 267-292.

Baron, R. y Richardson, D. (1994). Human Agression. New York: Plenum Press.

Berger, C. (2011). Agresividad, prosocialidad y estatus social: identificando perfiles admirados entre preadolescentes chilenos. Magis, 4(8), 357-368.

Briñol, P., De la Corte, L. y Becerra, A. (2001). Qué es persuasión. Madrid: Biblioteca Nueva.

Briñol, P., Horcajo, J., Becerra, A., Falces, C. y Sierra, B. (2002). Cambio de actitudes implícitas. Psicothema, 14, 771-775.

Cabero, J. (2002) Mitos de la sociedad de la información: sus impactos en la educación. En Aguilar, M.V. (Coord.), Cultura y educación en la sociedad de la información (pp. 17-38). La Coruña: Netbiblo.

Cabero, J. y Romero, R. (2001). Violencia, juventud y medios de comunicación. Comunicar, 17, 126-132.

Cantera, L. y Blanch, J. (2010). Percepción social de la violencia en la pareja desde los estereotipos de género. Intervención Social, 19(2), 121-127.

Cantera, L. y Gamero, V. (2007). La violencia en la pareja a la luz de los estereotipos de género. Psico, 38(3), 233-237.

Cárdenas, M. y Barrientos, J. (2008). Actitudes explícitas e implícitas hacia los hombres homosexuales en una muestra de estudiantes universitarios en Chile. Psykhé, 17(2), 17-35.

Chóliz, M. (2002). Motivos secundarios II: conducta de ayuda y agresión. En F. Palmero, E. G. Fernández-Abascal, F. Martínez y M. Chóliz (Eds.), Psicología de la motivación y emoción (pp. 253-285). Madrid: McGrawHill.

Consejo Nacional de Televisión. (2009). Televisión y jóvenes. Recuperado de http://www.cntv.cl/prontus_cntv/site/ artic/20110317/asocfile/20110317140840/estudio_ television_y_jovenes.pdf

Del Valle, C., Denegri, M. y Chávez, D. (2012). Alfabetización audiovisual y consumo de medios y publicidad en universitarios de Pedagogía en Chile. Comunicar, 19(38), 183-191.

Fazio, R. H. y Olson, M. A. (2003). Implicit measures in social cognition research: Their meaning and use. Annual Review of Psychology, 54, 297-327.
Fazio, R. H., Sanbonmatsu, D. M., Powell, M. C. y Kardes, F. R. (1986). On the automatic activation of attitudes. Journal of Personality and Social Psychology, 50, 229-238.

Ferguson, C. J. y Beaver, K. M. (2009). Natural born killers: The genetic origins of extreme violence. Aggression and Violent Behavior, 15(5), 286-294. doi:10.1016/j.avb.2009.03.005

Ferguson, C. J., Ivory, J. D. y Beaver, K. M. (2013). Genetic, maternal, school, intelligence and media use predictors of adult criminality: A longitudinal test of the catalyst model in adolescence through early adulthood. Journal of Aggression, Maltreatment y Trauma, 22, 1-14. doi: 10.1080/10926771.2013.785457

González, M. D. (2000). Conducta prosocial: evaluación e intervención. Madrid: Morata.

Greenwald, A. G. y Banaji, M. R. (1995). Implicit social cognition: Attitudes, self-esteem, and stereotypes. Psychological Review, 102(1), 4-27.

Greenwald, A. G., McGhee, D. E. y Schwartz, J. L. K. (1998). Measuring individual differences in implicit cognition: The implicit association task. Journal of Personality and Social Psychology, 74(1), 464-480.

Greenwald, A. y Nosek, B. (2001). Health of Implicit Association Test at age 3. Zeitschrift für Experimentelle Psychologie, 48, 85-93.

Greenwald, A. G., Nosek, B. A. y Banaji, M. R. (2003). Understanding and using the Implicit Association Test: I. An improved scoring algorithm. Journal of Personality and Social Psychology, $85,197-216$.

Gunter, B. (1996). Acerca de la violencia de los media. En J. Brayant y D. Zillmann (Comps.), Los efectos de los medios de comunicación. Investigaciones y teorías (pp. 223-286). Barcelona: Paidós.

Igartúa, J. (2002). Teoría sobre los efectos de la violencia en los medios: una revisión. Cultura y Educación, 14(1), 17-32.

Inglés, C. J., Benavides, G., Redondo, J., García-Fernández, J. M., RuizEsteban, C., Estévez, C., y Huéscar, E. (2009). Conducta prosocial y rendimiento académico en estudiantes españoles de educación secundaria obligatoria. Anales de Psicología, 25, 93-101.

Murray, J. P. (2008). Media Violence. The effects are both real and strong. American Beahavioral Scientist, 51(8), 1212-1230. doi: 10.1177/0002764207312018

Murray, J. P., Liotti, M., Ingmundson, P., Mayberg, H. S., Pu, Y., Zamarripa,...Fox, P. T. (2006). Children's brain response to TV violence: Functional Magnetic Resonance Imaging (fMRI) of video viewing in 8-13 year-old boys and girls. Media Psychology, 8(1), 25-37.

Navarro, A. (2003). Cultura, televisión y violencia en América Latina: el caso chileno. Recuperado de http://lanic.utexas.edu/ project/etext/llilas/cpa/spring03/culturaypaz/navarro.pdf

Organización Panamericana de la Salud. (2002). Informe mundial sobre la violencia y la salud: resumen. Recuperado de http:// whqlibdoc.who.int/publications/2002/9275324220_spa.pdf 
Organización Panamericana de la Salud. (2005). La violencia, un problema de Salud Mundial. Futuros, 10(3). Recuperado de http://www.revistafuturos.info/futuros_10/viol_salud2.htm

Pecora, N., Murray, J. P. y Wartella, E. (2007). Children and television: 50 years of research. Mahwah, N. J.: Kawrence Earlbaum.

Petty, R. E. y Cacioppo, J. T. (1986). Communication and persuasion: Central and peripheral routes to attitude change. New York: Springer-Verlag.

Petty, R. E. y Wegener, D. T. (1998). Attitude change: Multiple roles for persuasion variables. En D. Gilbert, S. Fiske y G. Lindzey (Eds.), The Handbook of Social Psychology (pp. 323-390). New York: McGraw-Hill.
Serrano, G., El-Astal, S. y Faro, F. (2004). La adolescencia en España, Palestina y Portugal: análisis comparativo. Psicothema, 16, 468-475.

Serrano, A. e Iborra, I. (2005). Violencia entre compañeros en la escuela. Centro Reina Sofía para el Estudio de la Violencia. Recuperado de http://213.0.8.18/portal/Educantabria/ RECURSOS/Materiales/Biblestinv/Informe_Violencia_entre_ compa\%C3\%B1eros_en_la_escuela.pdf

Silva, A. (2003). Conducta antisocial: un enfoque psicológico. México D. F.: Pax México.

Wilson, T. D., Lindsey, S. y Schooler, T. Y. (2000). A model of dual attitudes. Psychological Review, 107, 101-126. doi: 10.1037/0033-295X.107.1.101 